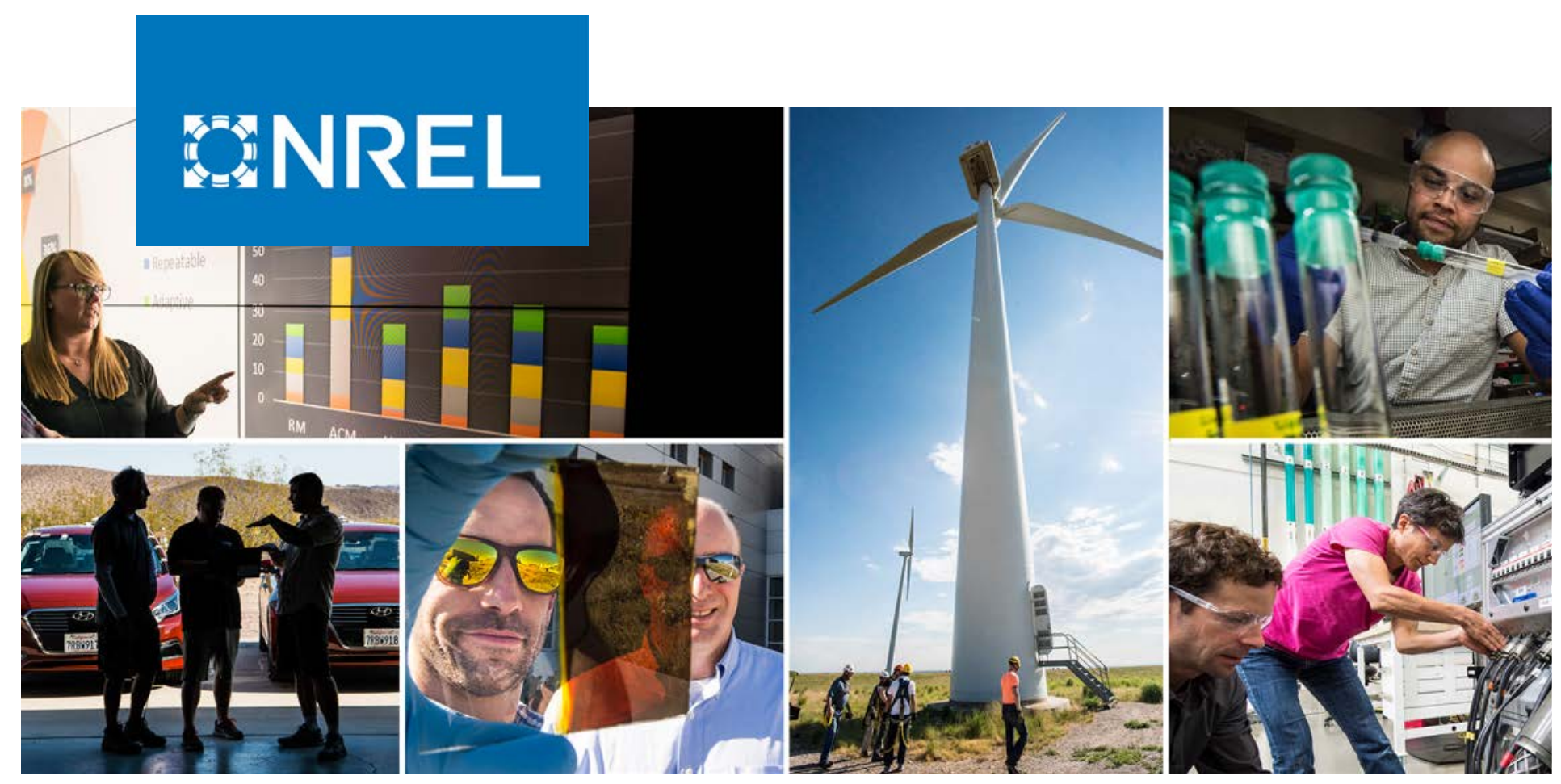

\title{
A Retrospective Analysis of Distributed Solar Interconnection Timelines and Related State Mandates
}

Emily S. Fekete,${ }^{1}$ Jesse R. Cruce,${ }^{1}$ Shiyuan Dong, ${ }^{1}$ Eric O'Shaughnessy, ${ }^{2}$ and Jeffrey J. Cook ${ }^{1}$

1 National Renewable Energy Laboratory

2 Clean Kilowatts, LLC

NREL is a national laboratory of the U.S. Department of Energy

Office of Energy Efficiency \& Renewable Energy

Operated by the Alliance for Sustainable Energy, LLC

This report is available at no cost from the National Renewable Energy Laboratory (NREL) at www.nrel.gov/publications.
Technical Report

NREL/TP-6A20-81459

January 2022 


\title{
GNREL
}

\section{A Retrospective Analysis of Distributed Solar Interconnection Timelines and Related State Mandates}

\author{
Emily S. Fekete,${ }^{1}$ Jesse R. Cruce,,${ }^{1}$ Shiyuan Dong, ${ }^{1}$ Eric \\ O'Shaughnessy, ${ }^{2}$ and Jeffrey J. Cook ${ }^{1}$
}

1 National Renewable Energy Laboratory

2 Clean Kilowatts, LLC

\section{Suggested Citation}

Fekete, Emily S., Jesse R. Cruce, Shiyuan Dong, Eric O'Shaughnessy, and Jeffrey J. Cook. 2022. A Retrospective Analysis of Distributed Solar Interconnection Timelines and Related State Mandates. Golden, CO: National Renewable Energy Laboratory. NREL/TP6A20-81459. https://www.nrel.gov/docs/fy22osti/81459.

NREL is a national laboratory of the U.S. Department of Energy Office of Energy Efficiency \& Renewable Energy Operated by the Alliance for Sustainable Energy, LLC

This report is available at no cost from the National Renewable Energy Laboratory (NREL) at www.nrel.gov/publications.

Contract No. DE-AC36-08GO28308
Technical Report

NREL/TP-6A20-81459

January 2022

National Renewable Energy Laboratory 15013 Denver West Parkway Golden, CO 80401

303-275-3000 • www.nrel.gov 


\section{NOTICE}

This work was authored in part by the National Renewable Energy Laboratory, operated by Alliance for Sustainable Energy, LLC, for the U.S. Department of Energy (DOE) under Contract No. DE-AC36-08GO28308. Funding provided by the U.S. Department of Energy Office of Energy Efficiency and Renewable Energy Solar Energy Technologies Office. The views expressed herein do not necessarily represent the views of the DOE or the U.S. Government.

This report is available at no cost from the National Renewable Energy Laboratory (NREL) at www.nrel.gov/publications.

U.S. Department of Energy (DOE) reports produced after 1991 and a growing number of pre-1991 documents are available free via www.OSTI.gov.

Cover Photos by Dennis Schroeder: (clockwise, left to right) NREL 51934, NREL 45897, NREL 42160, NREL 45891, NREL 48097, NREL 46526.

NREL prints on paper that contains recycled content. 


\section{Acknowledgments}

This work was funded by the U.S. Department of Energy's Solar Energy Technologies Office. The authors would like to thank NREL reviewers Kristen Ardani, Daniel Bilello, Mike Coddington, and David Narang, U.S. Department of Energy reviewers Abigail Randall and Ammar Qusaibaty, and the following external reviewers: Mike Hyland (Southern Maryland Electric Cooperative), Debra Santiago (Kauai Island Utility Cooperative), Joe White (Consolidated Edison), Aaron Anaya (Orange \& Rockland Utilities), Steve Letendre (Freedom Forever), and Eric Jung (Titan Solar Power). The authors would also like to anonymously thank all of the interviewees who contributed their expertise to this study. 


\section{List of Acronyms}

$\begin{array}{ll}\text { AHJ } & \text { authority having jurisdiction } \\ \text { DER } & \text { distributed energy resource } \\ \text { FERC } & \text { Federal Energy Regulatory Commission } \\ \text { IEEE } & \text { Institute of Electrical and Electronics Engineers } \\ \text { IOU } & \text { investor-owned utility } \\ \text { kW } & \text { kilowatt } \\ \text { MW } & \text { megawatt } \\ \text { NREL } & \text { National Renewable Energy Laboratory } \\ \text { PII } & \text { permitting, inspection, and interconnection } \\ \text { PSC } & \text { public service commission } \\ \text { PTO } & \text { permission to operate } \\ \text { PUC } & \text { public utilities commission } \\ \text { PV } & \text { photovoltaic } \\ \text { SolarTRACE } & \text { Solar Time-Based Residential Analytics and Cycle Time Estimator } \\ \text { UL } & \text { Underwriters Laboratories }\end{array}$




\section{Executive Summary}

Most distributed residential photovoltaic (PV) systems must secure an interconnection agreement prior to operation that ensures the local electrical system will operate safely within the broader electrical grid. PV installers generally submit an interconnection application to the local utility that provides all the necessary details the utility needs to evaluate the proposed system. To encourage timely execution of this process, many states' utility commissions have established mandates that limit the maximum number of days allowed for utility review and approval of interconnection for certain small, often residential applications.

In this paper, we derive the median and range of cycle times for the pre-installation approval phase of the interconnection process (i.e., from application submission to approval by the utility) across 24 U.S. states, using a data set of approximately 170,000 projects. We evaluate the percentage of projects that are approved within respective state-mandated timelines from 20172019. We further evaluate how timelines have evolved since 2012 for a subset of five states: Arizona, California, Colorado, New Jersey, and New York. The analyses are divided into two size ranges: systems that are $\leq 10$ kilowatts $(\mathrm{kW})$, and systems that are $11-50 \mathrm{~kW}$.

As of 2020, state-mandated interconnection application timelines for the pre-installation approval phase ranged from 10 to 40 business days, whereas state-level median approval timelines ranged from 0 to 23 days (Figure ES-1). We find that short approval timelines do not always occur in states with more stringent timeline mandates, and likewise, that the slowest completion timelines do not necessarily coincide with the least stringent mandates.

Although median review and approval timelines in each state meet respective mandates, we found that $8 \%$ of all PV system applications in the data set were not approved within statemandated timelines. While utilities approve projects within mandated timeframes more often than not, utilities across seven states met these mandates $95 \%$ of the time (or more) for systems $\leq 10 \mathrm{~kW}$, and utilities in six states met these mandates $95 \%$ of the time (or more) for systems $11-$ $50 \mathrm{~kW}$. This suggests that many PV system projects are not approved within state-mandated timelines. However, the causes of approval delay (e.g., utility delays or contractor errors/design delays) are unknown, and therefore require additional research. 


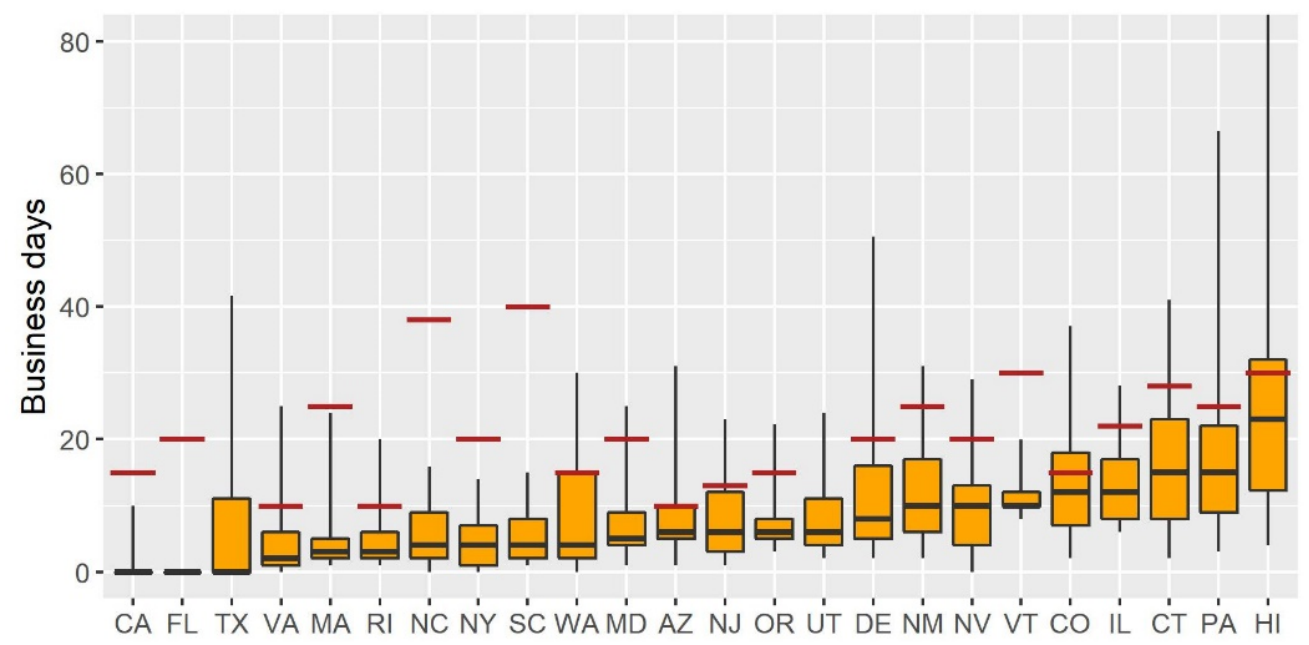

Figure ES-1: State-level pre-installation application approval timelines for projects $\leq 10 \mathrm{~kW}$

Whiskers denote the $5^{\text {th }}$ and $95^{\text {th }}$ percentiles, black bars denote the median, and red bars denote the state requirements.

Although some applications are not reviewed and approved within state-mandated timelines, preinstallation approval process timelines appear to have declined since NREL's prior analysis, which was conducted in 2015 (Ardani et al. 2015). For projects $\leq 10 \mathrm{~kW}$ in the five states included in the retrospective analysis, the median pre-installation approval process cycle time dropped from 10-32 business days to $0-12$ business days (a decline of 57\%-100\%). For projects $11-50 \mathrm{~kW}$, the median cycle time dropped from 10-25 business days to 4-14.5 business days (a decline of $44 \%-74 \%$ ).

To understand how utility interconnection processes have evolved and the impact these changes may have had on pre-installation approval timelines, we interviewed personnel from 13 utilities that operate in seven states. These interviews indicated that there are several practices that have been voluntarily implemented or required by regulators to help utilities decrease their overall timelines and comply with state mandates.

Interviewees identified two key process changes that could explain some of the review and approval time savings:

- The proliferation of online interconnection application submission and/or online fee payment portals

- Elimination of pre-installation approval application processes.

Additional research is required to evaluate whether the review and approval time savings identified here are valid, what effect individual process changes may have had on these timelines, what effects delayed timelines have, and why some projects do not get approved within mandated timelines. 


\section{Table of Contents}

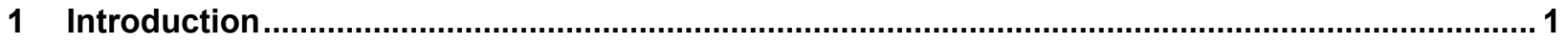

2 Understanding Interconnection Processes and Timelines ..................................................... 3

2.1 State-Mandated Interconnection Timeline Requirements ..................................................... 3

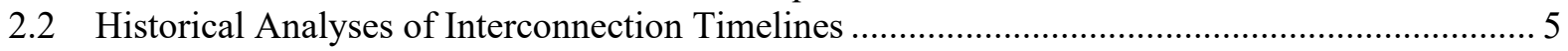

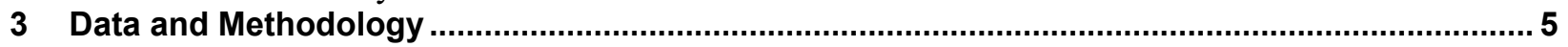

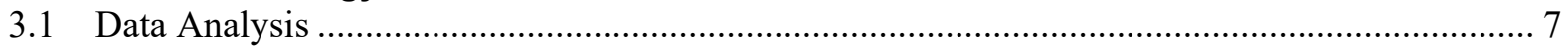

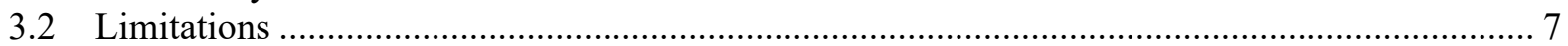

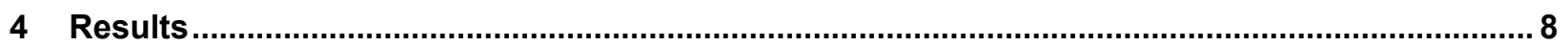

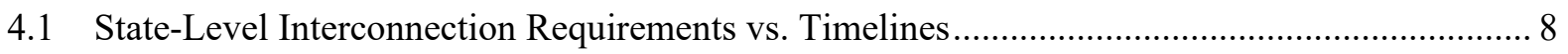

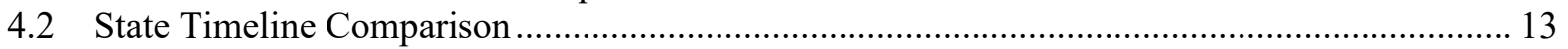

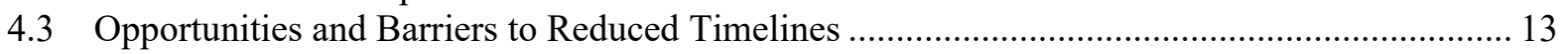

4.3.1 Practices To Improve Interconnection Timelines ........................................................ 14

4.3.2 Common Barriers for Interconnection Applications and Practices To Overcome Them

5 Conclusions

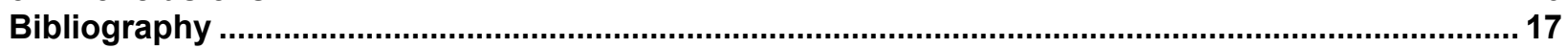




\section{List of Figures}

Figure 1: PV building permitting, inspection, and interconnection process (O'Shaughnessy et al. 2022)... 1 Figure 2: PV system installations by state in the study data set....................................................... 6

Figure 3: State-level pre-installation application approval timelines for projects $\leq 10 \mathrm{~kW} \ldots \ldots \ldots \ldots \ldots \ldots \ldots . . .12$

Figure 4: State-level pre-installation application approval timelines for projects $11-50 \mathrm{~kW} \ldots \ldots \ldots \ldots \ldots \ldots \ldots . . . . .12$

\section{List of Tables}

Table 1: Interconnection Phases With State-Mandated Timelines ........................................................... 4

Table 2: Projects Meeting Pre-Installation Approval Timeline State Requirements ................................ 10

Table 3: State Timeline Comparison of Pre-Installation Approval Phase ............................................... 13 


\section{Introduction}

In the United States, residential photovoltaic (PV) systems typically require a building permit issued by the authority having jurisdiction (AHJ) (e.g., city or county government) and an interconnection agreement issued by the utility providing electric service to the residential customer. An interconnection agreement is a contract between a customer and a utility company that governs the operation of a distributed generator within the utility's power system (Basso 2014). These agreements include technical requirements that must be met to ensure that the grid will operate safely with each new distributed energy resource (DER) addition (e.g., residential or commercial PV system, energy storage system, or other type of DER).

Annual residential PV installations in the United States have increased from approximately 54,000 systems in 2010 to over 419,000 systems in 2020 (Wood Mackenzie 2021). This growth coincides with an increased volume of applications across permitting authorities and utilities, which may result in application backlogs and longer review and approval timelines. Longer interconnection timelines may contribute to higher costs for installers, delays in PV system operation, increased project cancellations, customer dissatisfaction, and lower overall PV adoption rates (Cook et al. 2021a; O'Shaughnessy et al. 2019; Tayler 2019).

Residential PV system permitting and utility interconnection application reviews and approvals typically occur in parallel. While the local government has the authority to review and approve permits to build, the utility has the authority to approve applications for interconnection to the electrical grid (Figure 1). In this report, we focus only on the pre-installation approval phase (displayed in Figure 1), because it allows us to focus on the processes solely within the purview of the utility.

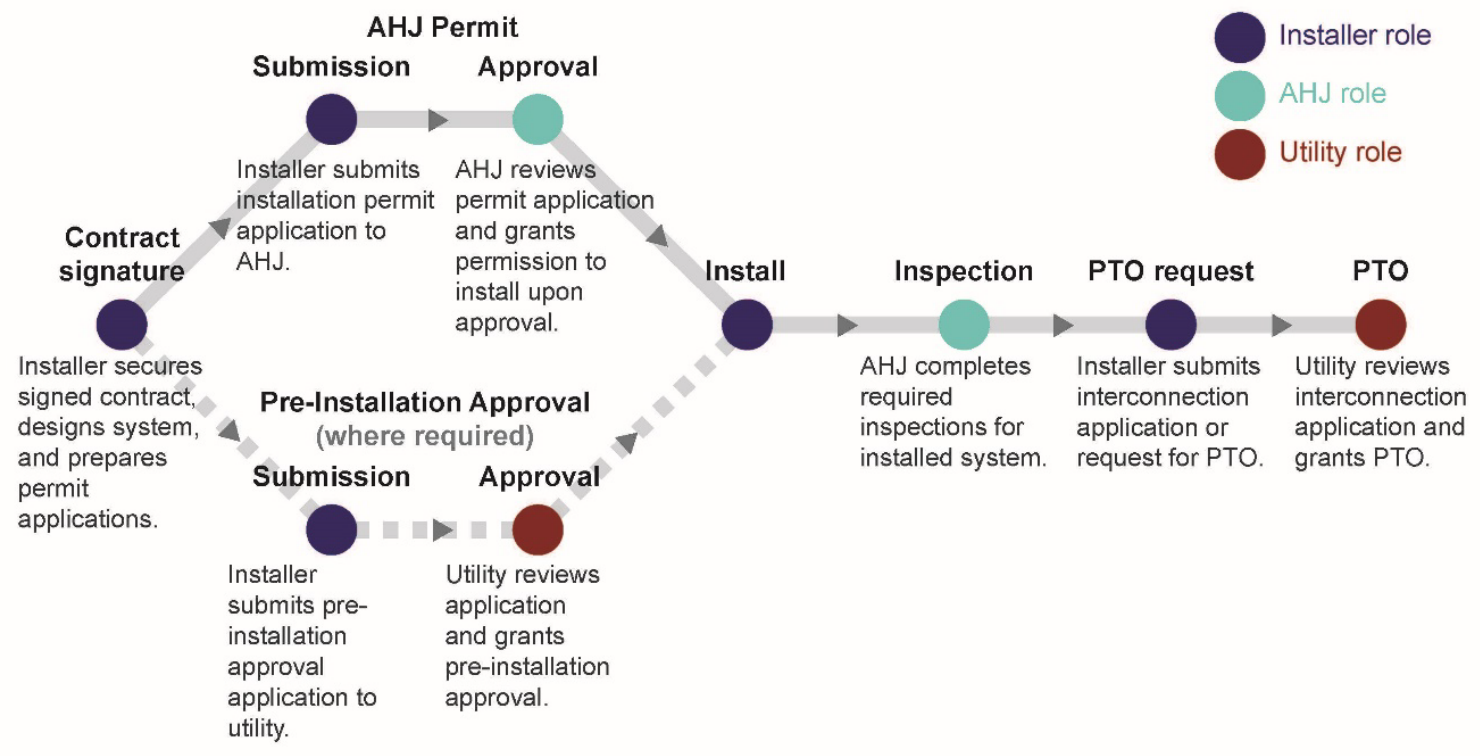

Figure 1: PV building permitting, inspection, and interconnection process (O'Shaughnessy et al. 2022) 
Many utilities have - either voluntarily or otherwise - adopted changes to their interconnection application review and approval processes to make these processes more efficient, including developing online submission portals and completing their reviews and approvals within a specified time window. These efficiencies have been driven by the large volume of interconnection applications coupled with staffing constraints and in some cases, mandates. Most mandates have been imposed by state regulators, such as a public utilities commission (PUC) or a public service commission (PSC). ${ }^{1}$ Some commissions have established a maximum allowable timeline, and in many cases, penalties are assessed if a utility does not meet the mandated timeline. Many electric utilities are cooperatives or municipal governments, and therefore are not under the authority of the state PUC/PSC, but rather are under the governance of their board of directors (in the case of cooperatives) or city leadership (in the case of municipals).

It is not widely reported whether utilities are currently meeting state-mandated review and approval timelines and how this compares to historic performance. To answer these questions, we document state-level timeline mandates, collect interconnection timeline data, and interview utilities to gain more insight into their processes and best practices. We utilize a data set of approximately 170,000 distributed PV systems of up to 50 kilowatts $(\mathrm{kW})$ that were installed between 2017 and 2019 in 24 states to evaluate interconnection timelines.

We find that while median pre-installation approval timelines in each state meet the respective state-level mandates, $8 \%$ of all PV systems in the data set do not meet state-mandated preinstallation approval timelines. Nevertheless, timelines appear to have decreased since 2014 for the five states evaluated. Finally, our interviews suggest that (1) switching to online applications is helpful but not sufficient for reducing review timelines, and (2) elimination of the preinstallation approval requirement benefits timelines but may not be feasible for all utilities in all markets.

\footnotetext{
${ }^{1}$ These state agencies regulate the services and rates of utilities, most commonly investor-owned utilities (IOUs).
} 


\section{Understanding Interconnection Processes and Timelines}

Most utilities have two stages in the interconnection process for residential PV: (1) the preinstallation approval phase and (2) the permission to operate, or PTO, stage (post-installation), as shown in Figure 1. ${ }^{2}$ The first stage, pre-installation approval, is the focus of this report. Typically, this stage starts when an installer/developer submits an interconnection application to the local utility. Once the application package is received, the utility reviews the application for completeness (if not complete, it is returned). Then, the application is reviewed to ensure the system as designed would not be problematic for the distribution system. If no concerns are present, the utility approves the interconnection agreement.

After having concurrently obtained an installation permit from the AHJ, the installer will sign the interconnection agreement and install the system, then proceed to have the installed system inspected by the AHJ. The building inspector from the AHJ will sometimes notify the utility that the system permit was approved and is ready for meter changes/installation. After taking these steps, the installer proceeds to the second stage and requests that the utility grant PTO. In this process, the utility reviews related documents (e.g., proof of local jurisdiction permit and inspection results) and may conduct their own inspection of the installed system to ensure that the inverter and PV modules match the interconnection application and to check smart inverter settings. In either case, the inspections ensure that the PV system follows the design submitted by the installer and that it meets all the local jurisdiction and utility requirements, confirming that the system is ready to be safely interconnected. Once documentation has been submitted and inspections completed, the utility can review the project and grant PTO. However, the actions included in the PTO phase timeline vary by a state's and utility's definition of the process. In some cases, PTO may include a witness test or inspection or a verification of inverter settings, and in other cases, the PTO timeline by definition only begins after the inspection is complete.

Although most utilities follow the two-stage approval process, some utilities - including the three largest investor-owned utilities (IOUs) in California-have adopted a post-installation interconnection application that consolidates the pre- and post-installation applications into one application that is submitted after installation. Under this streamlined practice, installers can construct PV systems within a set size limitation using approved equipment without waiting for pre-installation approval from utilities, reducing customer wait times (Barnes et al. 2016).

\subsection{State-Mandated Interconnection Timeline Requirements}

Some of the differences in utility processes have been mandated by state PSCs or PUCs. These commissions set state interconnection rules to regulate certain utility interconnection processes

\footnotetext{
${ }^{2}$ Most utilities have several types of interconnection applications based on technology type and size, and allowable review times are often longer for larger PV systems. There are many different interconnection application approaches used by regulated utilities in the United States. Rooftop PV systems are often very simple to review for most utilities, whereas larger systems or non-inverter-based resources require a more detailed study and a longer time allowance for studies.
} 
according to U.S. codes and standards, such as UL 1741 and IEEE $1547 .{ }^{3}$ These regulatory agencies can also set maximum allowable timeline requirements for defined interconnection phases as executed by utilities; these phases are summarized in Table 1 . When the mandates are not met, the regulated utilities may face significant penalties. Recently, the Minnesota PUC fined Xcel Energy \$1 million for interconnection failures related to customer complaints and significant timeline delays for community solar gardens (Brown 2021).

Table 1: Interconnection Phases With State-Mandated Timelines

\begin{tabular}{ll}
\hline $\begin{array}{l}\text { Interconnection } \\
\text { Process Phase }\end{array}$ & Definition of Timeline Requirement \\
\hline Pre-Application Report & $\begin{array}{l}\text { The number of business days a utility may take to conduct a nonbinding } \\
\text { report of information specific to a proposed PV system, as requested by } \\
\text { system installer or customer before the application is submitted. }\end{array}$ \\
$\begin{array}{l}\text { Pre-Application } \\
\text { Information Request }\end{array}$ & $\begin{array}{l}\text { The number of business days the utility has to respond to a request for } \\
\text { information by a customer or PV system installer; this may include an } \\
\text { operating agreement, application forms, technical requirements, } \\
\text { specifications, listing of certified equipment, application fee information, } \\
\text { applicable rate schedules, and metering requirements, among other } \\
\text { information. }\end{array}$
\end{tabular}

Pre-Installation Approval $^{*}$

The number of business days from the date a PV installer submits an interconnection application to the utility to the date the installer receives approval from the utility to install the PV system. This timeframe combines utility reviews for application completeness and compliance with technical requirements and-when included in state-level mandates - the time needed to send the agreement to the installer.

Study/Supplemental Review

The number of business days that the utility may take to conduct a supplemental review of the system, when necessary. The supplemental review may include more in-depth engineering screens than the initial review process if initial screens are not met.

Final Agreement Paperwork/PTO

The number of business days the utility has to send the final agreement paperwork granting PTO. Inclusions in this timeline vary by state and utility; for some, the timeline includes a witness test or the inspection itself, and for others, it only includes the time from when the inspection is completed to the time the paperwork is sent.

Total Maximum The maximum total number of business days that a utility may take for the Timeline entire interconnection process.

${ }^{*}$ Phases that are considered within the purview of this report

${ }^{3}$ UL 1741 is an Underwriters Laboratories (UL) Standard of Inverters, Converters, Controllers and Interconnection System Equipment for Use with Distributed Energy Resources. UL 1741 SA and UL 1741 SB are recent versions that support smart inverter functions: https://standardscatalog.ul.com/ProductDetail.aspx?productId=UL1741. IEEE 1547 is the Institute of Electrical and Electronics Engineer's Standard for Interconnection Interoperability of Distributed Energy Resources with associated Electric Power System Interfaces:

https://standards.ieee.org/standard/1547-2018.html. 
State-mandated requirements for interconnection phases often vary by state and project size. Many PUCs require that small systems (typically less than $10 \mathrm{~kW}$ ) receive an expedited or simplified review process because their impacts on the utility grid are relatively small. ${ }^{4}$ For example, New Jersey utilities may take a maximum of 13 business days for application review of projects up to $10 \mathrm{~kW}$, whereas projects up to 2 megawatts (MW) receive an additional 5 days (for a total of 18 business days maximum). In comparison, New York allows utilities a maximum of 20 business days for all projects under $50 \mathrm{~kW}$ (10 business days to determine completeness and 10 business days to review the application). ${ }^{5}$ Faster timelines for smaller projects may also be associated with eligibility to waive certain review requirements, such as intensive engineering reviews, or exemption from certain reviews altogether, as in California (Taylor 2019; Bird et al. 2018; Stanfield et al. 2013).

\subsection{Historical Analyses of Interconnection Timelines}

Ardani et al. (2015) were among the first to evaluate interconnection review timelines for distributed PV systems. Through a cycle time assessment of more than 30,000 PV systems installed from 2012 to 2014, they found that the entire PV install process, from interconnection submission to PTO (i.e., interconnection application, system installation, inspection by the permitting AHJ, and finally PTO), took 53 business days at the median. Utility reviews at the pre-installation and PTO stages were found to take a median of 18 and 10 business days, respectively - though the authors found significant variation in the data, and many projects experienced much longer timelines.

Similarly, Barnes et al. (2016) surveyed installers across 20 states and Washington, D.C., about their average timelines in 2014 and 2015. The installers surveyed covered 117,814 preinstallation applications and 151,643 PTO applications. The authors estimated that preinstallation processes took an average of 18 calendar days and PTO took an average of 45 calendar days, and they suggested that timelines may have been lengthening for both stages. However, these estimates were averaged from self-reported data from installers, and there is wide variation in the reported results across utilities.

By utilizing a project-level data set of recent PV installs that includes additional states and a higher volume of projects, we build on this earlier work to identify how utilities are complying with state-mandated timelines, how timelines have evolved overall, and what factors might explain the length of interconnection application reviews and approvals today.

\section{Data and Methodology}

This study utilizes the data set collected and published by NREL as part of the Solar Time-Based Residential Analytics and Cycle Time Estimator (SolarTRACE) tool (NREL 2021; Cook et al.

\footnotetext{
${ }^{4}$ Most state interconnection rules are for regulated utilities and are based on the Federal Energy Regulatory Commission (FERC) Small Generator Interconnection Procedures (SGIP). These rules are then interpreted by each regulated utility, and the specific utility procedures are published along with interconnection applications. ${ }^{5}$ New York State Standardized Interconnection Requirements and Application Process For New Distributed generators and Energy Storage Systems $5 \mathrm{MW}$ or Less Connected in Parallel with Utility Distribution Systems: https://www3.dps.ny.gov/W/PSCWeb.nsf/96f0fec0b45a3c6485257688006a701a/dcf68efca391ad6085257687006f3 96b/\$FILE/December\%202019\%20SIR\%20-\%20FINAL\%20-\%20Clean.pdf
} 
2021b). ${ }^{6}$ The data set included time-stamped observations of key dates for ten medium-to-large $\mathrm{PV}$ projects during the installation process. This study uses a subsample of the data set, keeping only projects that (1) are PV-only (i.e., the study excludes projects with battery storage); (2) are $50 \mathrm{~kW}$ or less; and (3) were installed in the 24 states with state-mandated timelines for regulated utilities (discussed below). Not all dates for all projects were consistently tracked, but altogether, the data set includes utility pre-installation approval timeline data from 172,827 PV systems installed between 2017 and $2019 .{ }^{7,8}$ These systems represent 202 utilities in 24 states, as seen in Figure $2 .{ }^{9}$

\begin{tabular}{|c|c|c|c|c|c|c|c|c|c|c|c|}
\hline $\begin{array}{l}\text { WA } \\
101\end{array}$ & ID & MT & ND & MN & WI & & & $\begin{array}{c}\text { NY } \\
8256\end{array}$ & $\begin{array}{l}V T \\
535\end{array}$ & $\mathrm{NH}$ & ME \\
\hline $\begin{array}{l}\text { OR } \\
228\end{array}$ & $\begin{array}{c}\text { UT } \\
1981\end{array}$ & WY & SD & IA & $\underset{1469}{\mathrm{IL}}$ & MI & $\begin{array}{c}\text { PA } \\
3419\end{array}$ & $\begin{array}{c}\mathrm{NJ} \\
7577\end{array}$ & $\begin{array}{c}\mathrm{CT} \\
3474\end{array}$ & $\begin{array}{c}\text { MA } \\
9997\end{array}$ & \\
\hline \multirow[t]{3}{*}{$\begin{array}{c}\text { CA } \\
82049\end{array}$} & $\begin{array}{c}\text { NV } \\
11783\end{array}$ & $\begin{array}{c}\mathrm{CO} \\
3603\end{array}$ & $\mathrm{NE}$ & MO & IN & $\mathrm{OH}$ & WV & $\begin{array}{c}\mathrm{MD} \\
7712\end{array}$ & $\begin{array}{l}\mathrm{DE} \\
432\end{array}$ & $\begin{array}{r}\mathrm{RI} \\
421\end{array}$ & \\
\hline & $\underset{17971}{\mathrm{AZ}}$ & $\begin{array}{c}\text { NM } \\
2087\end{array}$ & KS & $\mathrm{AR}$ & KY & $\mathrm{TN}$ & $\begin{array}{l}\text { VA } \\
614\end{array}$ & DC & $\begin{array}{l}\text { NC } \\
160\end{array}$ & & \\
\hline & & & OK & LA & MS & $A L$ & GA & $\begin{array}{c}\text { SC } \\
3258\end{array}$ & & & \\
\hline AK & $\begin{array}{c}\mathrm{HI} \\
1098\end{array}$ & & $\begin{array}{c}\text { TX } \\
2150\end{array}$ & & & & & $\underset{2452}{\mathrm{FL}}$ & & & \\
\hline
\end{tabular}

Figure 2: PV system installations by state in the study data set

State-mandated timelines were collected for 24 states in the data set, including the five states analyzed by Ardani et al. (2015). Interconnection timeline requirement data was collected from state agencies and/or utility tariffs for PV systems $50 \mathrm{~kW}$ or smaller.

To supplement our analysis of the interconnection cycle time data, we conducted interviews with 13 utilities across seven states. The utilities that participated included eight IOUs, three electric cooperatives, and two publicly owned municipal utilities. Utility interviewees were selected based on a review of the utility data within the data set. The interviews were semi-structured and focused on identifying unique practices and challenges faced by utilities of varying sizes and types in implementing residential interconnection processes and completing reviews within statemandated timelines.

\footnotetext{
${ }^{6}$ Available at solarapp.nrel.gov/solarTRACE and data.nrel.gov/submissions/160.

${ }^{7}$ The original installer-provided data set consisted of approximately 503,000 projects, but only 172,827 both met the inclusion criteria and included sufficient utility pre-install approval process data.

${ }^{8}$ This study found that 16 utilities, including the three large IOUs in California, do not require pre-installation approval for projects $\leq 10 \mathrm{~kW}$; if not included in the data, pre-installation approval timelines for projects within these utilities were set to 0 days for analysis (based on the assumption that "no required approval" constitutes meeting the state approval timeline mandate for these projects).

${ }^{9}$ The 202 utilities represented in the data set include IOUs, municipal utilities, and cooperative utilities.
} 


\subsection{Data Analysis}

We compared the timelines in the data set to current state-mandated timelines. ${ }^{10}$ State-level timelines were based on a sample size of 30 or more project installations per state. Again, we only evaluated the pre-installation approval phase. The comparison included both median timelines (in business days) and the proportion of projects meeting the mandate (given as a percentage of the sample) for each size category in each state. Comparisons were made for two system size categories: projects $\leq 10 \mathrm{~kW}$ and projects $11-50 \mathrm{~kW}$.

Next, to evaluate how interconnection review and approval timelines have evolved over time, we compared the data from this study to a similar data set utilized in Ardani et al. (2015), which calculated timelines for more than 30,000 distributed PV systems (of $50 \mathrm{~kW}$ or less) installed between 2012 and 2014 across 87 utilities. We compared these results to current median timelines in Arizona, California, Colorado, New Jersey, and New York. Changes in median timelines were compared only for the pre-installation phase, given that the definition of the preinstallation approval process is consistent between all data sources considered (utilities, installers, state-mandated timeline requirements, and Ardani et al. (2015)), which is not the case for the PTO phase.

Although Barnes et al. (2016) also estimated interconnection timelines, we only used those from Ardani et al. (2015) for comparison in this study. The primary reason is that Barnes et al. (2016) did not perform their timeline calculations from a project-level data set, but rather estimated a volume-weighted average from self-reported data from surveyed installers. In contrast, both Ardani et al. (2015) and this study use time-stamped, project-level data from which interconnection timelines are subsequently calculated - thus, this study uses the same methodology as Ardani et al. (2015), allowing for more valid comparisons.

\subsection{Limitations}

The installer-provided data set used in this study generally only reported two dates associated with utility pre-installation approval timelines: application submission and pre-installation approval. As such, not all projects with timelines longer than the respective state mandates are necessarily out of compliance. For example, projects with incomplete or incorrect application submissions - or projects requiring design changes - may require multiple rounds of utility reviews and application resubmissions. Even if each round of utility reviews was within the state-mandated timeline, some of these projects may still be flagged as out of compliance if the installer used only the date of first submission in their data. Given that installers did not provide details on which submission date was used or whether resubmissions were required due to incomplete or incorrect submissions, it is not possible to separate projects with longer, noncompliant timelines from projects that simply required multiple reviews, each of which were within compliance. As such, the findings from this study likely represent a worst-case scenario for rates of noncompliance in each state.

An additional limitation of our analysis is that the data set utilized includes projects under the authority of IOUs, municipal utilities, and cooperative utilities. All projects in the data set are

\footnotetext{
${ }^{10}$ State-mandated timelines, the data from Ardani et al. (2015), and the results from the data set were converted to business days for analysis and comparison.
} 
used to derive a state-level median, which is then compared to the respective state-level timeline as mandated by the state's commission. Cooperative and municipal utilities may not fall under PUC or PSC regulation, but rather under the governance of their board of directors (cooperatives) or city leadership (municipals). Even so, IOUs encompass most of the projects included in the data set and are regulated by PUCs or PSCs. Further, we present the median, percentiles, and ranges to consider outliers that could be regulated by other utilities.

Finally, the data set used for analysis only contains project-level data submitted by installers, with no data submitted by utilities. Collecting data from both installers and utilities would provide a more complete picture of the review and approval process for each project. However, this data was not made available by utilities. Some states (California, Massachusetts, and New York) require certain utilities to publish data on their interconnection approval timelines. In each data set, there was significant variation in the reported interconnection review and approval timelines, making it unclear whether the timelines were valid (review and approval timelines frequently exceeded 300 days). There was also no way to compare our data with the public queue data to cross-reference timeline validity. Even so, the average review and approval timelines in these three states generally aligned with the timelines in our data. Given these concerns with the public data, and the fact that the data is publicly available in just three states, we rely on the installer data set alone.

\section{Results}

The results are organized into three sections. First, we compare state-level pre-installation approval interconnection timeline requirements to that of the observed review and approval times from the data. Second, we evaluate how median timelines have changed in the five states analyzed by Ardani et al. (2015). Last, we summarize the qualitative findings regarding interconnection review and approval times and related processes based on our interviews with utilities.

\subsection{State-Level Interconnection Requirements vs. Timelines}

Interconnection process mandates vary across the 24 states evaluated in this study, as seen in Table 2. Some mandates are set directly by the PUC/PSC for all regulated utilities in the state. Alternatively, the PUC/PSC may provide guidelines for mandates, after which each utility proposes its own targets for approval by the PUC/PSC (see the "utility- or state-specific mandate" column in Table 2).

Differences also exist between states in terms of the year the mandates were initially adopted and when they were last updated. For example, some states have updated their interconnection requirements as recently as 2019 , whereas others have not been updated since 2006 . Further, there is variation in the project sizes that mandates apply to, which don't always align with the size categories developed for our study $(\leq 10 \mathrm{~kW}$ and $11-50 \mathrm{~kW})$. For example, the state of New Mexico sets mandates for projects $\leq 10 \mathrm{~kW}$ and secondary mandates for projects $11 \mathrm{~kW}-2 \mathrm{MW}$. In these cases, the state mandates were adapted to the size categories used by this analysis in Table 2.

Not all states apply timeline mandates to the pre-installation approval process. Instead, both Texas and Utah set mandates for the total maximum interconnection time, spanning the entire 
time from submission of the pre-installation application to final PTO, rather than setting separate timelines for component phases. As such, timelines for projects from the data set could not be compared to state-level requirements in either Texas or Utah, though both states are included in Table 2 for reference. For those that do have set mandates, timeline requirements range from 10 to 40 days across both project size categories.

As seen in Table 2, the median pre-installation timelines for projects in each state meet the respective state mandates. Despite this result at the median, many projects have much longer timelines. Of the states analyzed in this study, seven ${ }^{11}$ have utilities that are collectively meeting the mandated timelines for $95 \%$ or more of projects $\leq 10 \mathrm{~kW}$ (indicated by the green cells in Table 2), namely, California, Florida, Massachusetts, North Carolina, New York, South Carolina, and Vermont. For projects $11-50 \mathrm{~kW}$, six states are meeting this $95 \%$ target (Massachusetts, North Carolina, New York, South Carolina, and Vermont, plus Maryland).

\footnotetext{
${ }^{11}$ Assuming that projects in utilities that do not require pre-installation approval still contribute to state-level medians with an equivalent timeline of 0 days each.
} 
Table 2: Projects Meeting Pre-Installation Approval Timeline State Requirements

\begin{tabular}{|c|c|c|c|c|c|c|c|c|c|c|}
\hline & & & \multicolumn{4}{|c|}{ Projects $\leq 10 \mathrm{~kW}$} & \multicolumn{4}{|c|}{ Projects $11-50 \mathrm{~kW}$} \\
\hline State & $\begin{array}{l}\text { Utility- } \\
\text { or State- } \\
\text { Specific } \\
\text { Mandate }\end{array}$ & $\begin{array}{c}\text { Year } \\
\text { Updated }\end{array}$ & $\begin{array}{l}\text { Number } \\
\text { of } \\
\text { Projects }\end{array}$ & Median & State Req. & $\begin{array}{c}\text { N (\%) Meeting } \\
\text { Timeline } \\
\text { Mandate }\end{array}$ & $\begin{array}{l}\text { Number } \\
\text { of } \\
\text { Projects }\end{array}$ & Median & State Req. & $\begin{array}{c}\mathrm{N}(\%) \text { Meeting } \\
\text { Timeline } \\
\text { Mandate }\end{array}$ \\
\hline$A Z^{*}$ & State & 2007 & 14,804 & 6 & 10 & $11,263(76 \%)$ & 3,167 & 7 & 10 & $2,381(75 \%)$ \\
\hline $\mathrm{CA}^{*}$ & State & 2018 & 81,792 & 0 & 15 & $79,055(97 \%)$ & 257 & 6 & 15 & $170(66 \%)$ \\
\hline $\mathrm{CO}^{*}$ & State & 2007 & 3,499 & 12 & 15 & $2,314(66 \%)$ & 104 & 15 & 15 & $55(53 \%)$ \\
\hline CT & State & 2019 & 2,784 & 15 & 28 & $2,412(87 \%)$ & 690 & 15 & 28 & $591(86 \%)$ \\
\hline $\mathrm{DE}$ & Utility & 2010 & 306 & 8 & 20 & $244(80 \%)$ & 126 & 7 & 25 & $104(83 \%)$ \\
\hline $\mathrm{FL}$ & State & 2018 & 2,385 & 0 & 20 & $2,362(99 \%)$ & 67 & 1 & 20 & $55(82 \%)$ \\
\hline $\mathrm{HI}$ & Utility & 2019 & 1,094 & 23 & 30 & $783(72 \%)$ & 4 & ** & $* *$ & ** \\
\hline IL & State & 2017 & 1,244 & 12 & 22 & $1,108(89 \%)$ & 225 & 10 & 22 & $205(91 \%)$ \\
\hline MA & State & 2016 & 8,341 & 3 & 25 & $7,965(95 \%)$ & 1,656 & 3 & 35 & $1,574(95 \%)$ \\
\hline MD & State & 2007 & 5,568 & 5 & 20 & $5,189(93 \%)$ & 2,144 & 6 & 30 & $2,062(96 \%)$ \\
\hline NC & State & 2015 & 123 & 4 & 38 & $123(100 \%)$ & 37 & 5 & 38 & $36(97.3 \%)$ \\
\hline $\mathrm{NJ}^{*}$ & State & 2019 & 6,545 & 6 & 13 & $5,316(81 \%)$ & 1,032 & 8 & 18 & $884(86 \%)$ \\
\hline NM & State & 2008 & 2,010 & 10 & 25 & $1,692(84 \%)$ & 77 & 16 & 30 & $59(77 \%)$ \\
\hline NV & Utility & 2018 & 10,679 & 10 & 20 & $1,692(84 \%)$ & 1,104 & 11 & 20 & $962(87 \%)$ \\
\hline$N Y^{*}$ & State & 2019 & 7,344 & 4 & 20 & $7,130(97 \%)$ & 912 & 4 & 15 & $879(96 \%)$ \\
\hline OR & State & 2009 & 216 & 6 & 15 & $196(91 \%)$ & 12 & ** & ** & ** \\
\hline PA & State & 2006 & 2,731 & 15 & 25 & $2,253(82 \%)$ & 688 & 16 & 30 & $527(77 \%)$ \\
\hline $\mathrm{RI}$ & Utility & 2018 & 399 & 3 & 10 & $344(86 \%)$ & 22 & ** & $\begin{array}{c}\text { No pre- } \\
\text { installation } \\
\text { approval } \\
\text { timeline } \\
\text { mandate } \\
\end{array}$ & $\mathrm{N} / \mathrm{A}$ \\
\hline SC & State & 2019 & 3,173 & 4 & 40 & $3,168(100 \%)$ & 85 & 7 & 40 & $84(99 \%)$ \\
\hline $\mathrm{TX}$ & State & 2017 & 1,988 & 0 & $\begin{array}{c}\text { No pre- } \\
\text { installation } \\
\text { approval } \\
\text { timeline } \\
\text { mandate }\end{array}$ & $N / A$ & 162 & 12 & $\begin{array}{c}\text { No pre- } \\
\text { installation } \\
\text { approval } \\
\text { timeline } \\
\text { mandate }\end{array}$ & N/A \\
\hline UT & State & 2018 & 1,845 & 6 & $\begin{array}{c}\text { No pre- } \\
\text { installation } \\
\text { approval } \\
\text { timeline } \\
\text { mandate } \\
\end{array}$ & N/A & 136 & 19 & $\begin{array}{c}\text { No pre- } \\
\text { installation } \\
\text { approval } \\
\text { timeline } \\
\text { mandate } \\
\end{array}$ & $\mathrm{N} / \mathrm{A}$ \\
\hline VA & State & 2009 & 441 & 2 & 10 & $361(82 \%)$ & 173 & 5 & 10 & $133(77 \%)$ \\
\hline VT & State & 2006 & 503 & 10 & 30 & $502(99 \%)$ & 32 & 12 & 30 & $31(97 \%)$ \\
\hline WA & State & 2019 & 81 & 4 & 15 & $61(75 \%)$ & 20 & ** & $* *$ & ** \\
\hline All states & & & 159,895 & 1 & & $147,321(92 \%)$ & 12,932 & 7 & & $11,143(86 \%)$ \\
\hline
\end{tabular}

*States that were included in the 2015 Ardani et al. study on interconnection timelines

**Insufficient data for analysis 
The rate of projects with pre-installation approval noncompliant timelines varies significantly by state. For projects $\leq 10 \mathrm{~kW}$, noncompliance rates range from $0 \%-36 \%$, whereas the range is $1 \%-$ $47 \%$ for projects $11-50 \mathrm{~kW}$. Across the entire data set, 14,363 projects (out of 172,827 total) do not meet the respective state-mandated pre-installation approval timelines, averaging $8 \%$ of projects $\leq 10 \mathrm{~kW}$ and $14 \%$ of projects $11-50 \mathrm{~kW}$.

Several states influence the high range of noncompliance rates. For example, more than $25 \%$ of projects $\leq 10 \mathrm{~kW}$ in Colorado and Hawaii do not meet the respective state-mandated timelines, and more than $25 \%$ of projects $11-50 \mathrm{~kW}$ in Arizona, California, and Colorado do not meet the respective state mandates. The high rates in these states may suggest that there are at least some projects that are not reviewed and approved within state-mandated timelines. This could be attributed to several factors, including incomplete or incorrect applications, design changes needed for safe operation on the grid, or approval delays on the utility's end. If the utility is at fault, noncompliance rates may leave individual utilities at risk for penalties from the PUC or PSC.

The range in timelines in the data is shown against the state-level requirements in Figure 3 (for projects $\leq 10 \mathrm{~kW}$ ) and Figure 4 (for projects $11-50 \mathrm{~kW}$ ). As seen in Figure 3, the states with the fastest utility timelines for projects $\leq 10 \mathrm{~kW}$ include California, Florida, Massachusetts, New York, North Carolina, Rhode Island, South Carolina, Virginia, and Washington. Each of these states has a median pre-installation approval timeline of 4 days or less, which is notable because both North Carolina and South Carolina have some of the least stringent requirements for this phase. In contrast, Virginia and Rhode Island have some of the most stringent requirements and the fastest utility timelines. Figure 4 illustrates timelines for projects $11-50 \mathrm{~kW}$, the fastest of which include Florida, Massachusetts, New York, Virginia, and North Carolina. These states all have median pre-installation approval timelines of 5 days or less. Of these, North Carolina and Massachusetts have some of the least stringent mandates across all 24 states analyzed, whereas New York and Virginia are among the most stringent. 


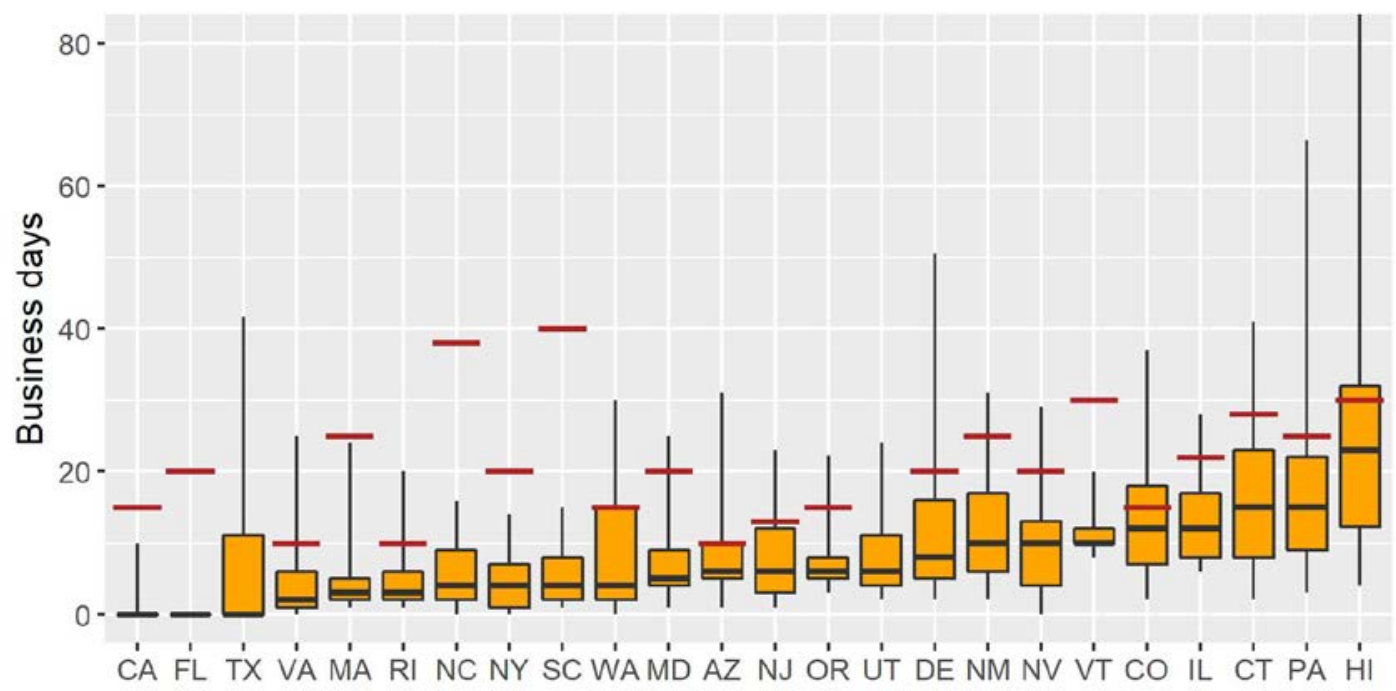

Figure 3: State-level pre-installation application approval timelines for projects $\leq 10 \mathrm{~kW}$ Whiskers denote the $5^{\text {th }}$ and $95^{\text {th }}$ percentiles, black bars denote the median, and red bars denote the state requirements. ${ }^{12}$

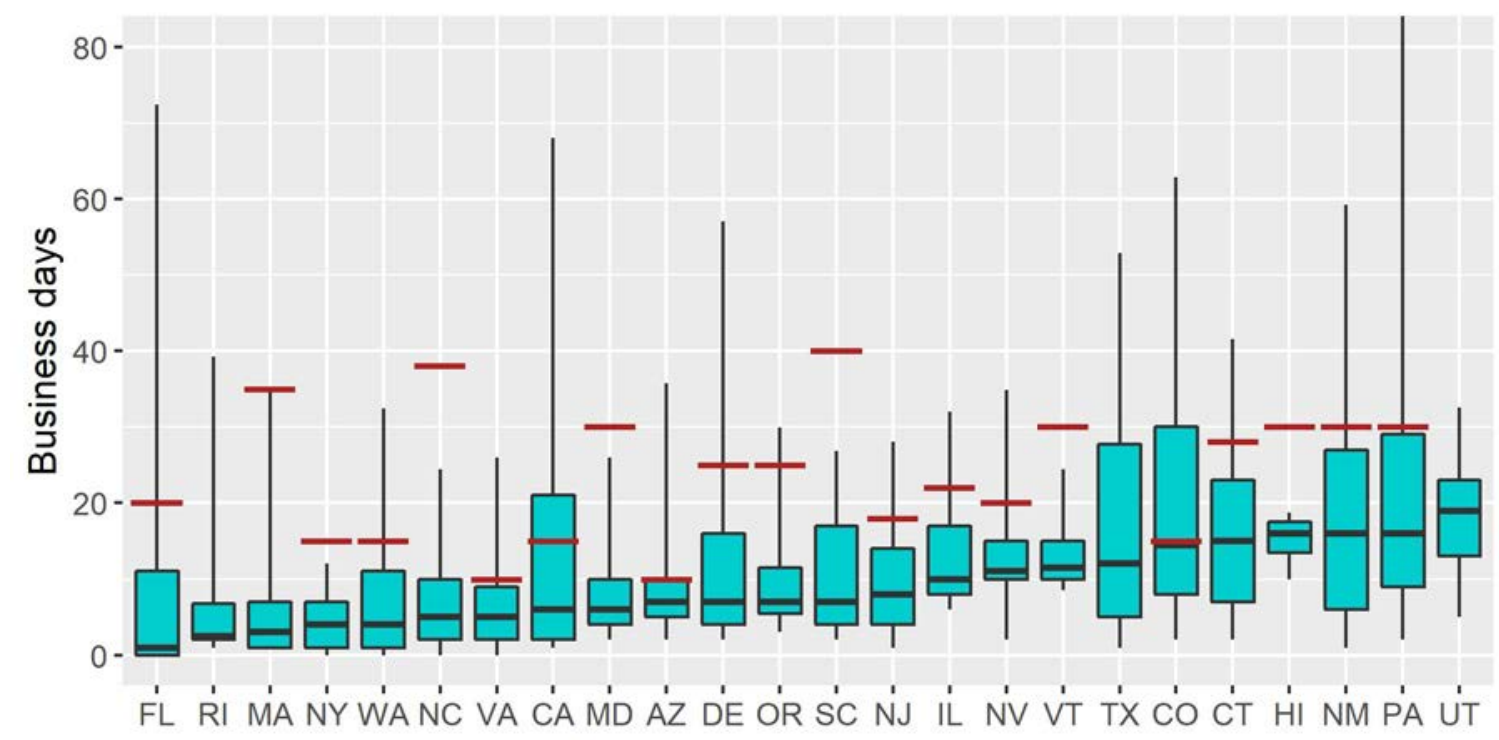

Figure 4: State-level pre-installation application approval timelines for projects $\mathbf{1 1 - 5 0 ~ k W ~}$

Whiskers denote the $5^{\text {th }}$ and $95^{\text {th }}$ percentiles, black bars denote the median, and red bars denote the state requirements. ${ }^{13}$

Figure 3 also depicts the states with the slowest utility timelines for projects $\leq 10 \mathrm{~kW}$, which include Colorado, Connecticut, Hawaii, Nevada, and Pennsylvania. Of these states, Hawaii and Connecticut have some of the least stringent requirements for the pre-installation phase.

Similarly, for projects 11-50 kW, Colorado, Connecticut, New Mexico, Pennsylvania, and Utah

${ }^{12}$ States without red bars do not have a mandated maximum timeline for the pre-installation phase.

${ }^{13}$ States without red bars do not have a mandated maximum timeline for the pre-installation phase. 
have among the longest state-level medians (Figure 4), and they also have more stringent mandated review and approval timelines. In fact, Colorado has one of the most stringent requirements for its size range. As both figures demonstrate, more stringent state mandates do not necessarily appear to coincide with shorter median review and approval times.

\subsection{State Timeline Comparison}

Historical median pre-installation approval timelines for PV projects $\leq 10 \mathrm{~kW}$ in Arizona, California, Colorado, New Jersey, and New York are shown in Table 3. When comparing the data set median timelines to those from Ardani et al. (2015), all five states exhibited at least a $50 \%$ reduction in their median pre-installation approval timelines. California utilities collectively displayed the most significant decrease, due to changes in the pre-installation approval phase. For example, Southern California Edison and Pacific Gas and Electric, two of the large IOUs in California, voluntarily chose to remove the pre-installation approval process for certain eligible systems, reducing pre-installation approval timelines from a median of 6 days to 0 .

Table 3: State Timeline Comparison of Pre-Installation Approval Phase

\begin{tabular}{|l|l|l|l|l|l|l|}
\hline \multicolumn{7}{|c|}{ Pre-Installation Approval Timeline (Business Days) } \\
\hline State & $\begin{array}{c}\text { 2012-2014 } \\
\text { Median }\end{array}$ & $\begin{array}{c}\text { 2017-2019 } \\
\text { Median }\end{array}$ & $\begin{array}{c}\text { \% } \\
\text { Change }\end{array}$ & $\begin{array}{c}\text { 2012-2014 } \\
\text { Median }\end{array}$ & $\begin{array}{c}\mathbf{2 0 1 7 - 2 0 1 9} \\
\text { Median }\end{array}$ & $\begin{array}{c}\text { \% } \\
\text { Change }\end{array}$ \\
\hline AZ & 22 & 6 & $-73 \%$ & 22 & 7 & $-68 \%$ \\
\hline CA & 20 & 0 & $-100 \%$ & 23 & 6 & $-74 \%$ \\
\hline CO & 32 & 12 & $-63 \%$ & 25 & 14.5 & $-42 \%$ \\
\hline NJ & 14 & 6 & $-57 \%$ & 15 & 8 & $-47 \%$ \\
\hline NY & 10 & 4 & $-60 \%$ & 10 & 4 & $-60 \%$ \\
\hline
\end{tabular}

We observed similar trends for projects that are 11-50 kW (Table 3, right). All five of the analyzed states displayed a $40 \%$ or greater reduction in median timelines between the two studies. The most significant decrease took place in California, where collectively, preinstallation medians were reduced from 23 to 6 business days. The fastest median timelines for the pre-installation phase were exhibited by New York utilities, at four business days, collectively. These findings suggest that utility pre-installation approval times have improved overall across the five states.

\subsection{Opportunities and Barriers to Reduced Timelines}

To identify what might be driving the reduction in review timelines in these states and potentially others, we discussed pre-installation approval processes and timelines with representatives from utilities of various sizes and ownership models. These interviews helped identify some potential best practices to create more efficient interconnection processes. 


\subsubsection{Practices To Improve Interconnection Timelines}

Our interviewees summarized several practices that can help create a more transparent and efficient interconnection process, including (1) online application submission and fee payment and (2) elimination of the pre-installation approval processes.

Online submission processes, where all application documents are uploaded on a single website that also tracks the status of the application, can benefit both the installer and the utility. NREL data suggests that, nationwide, at least 57 utilities are currently accepting applications via an application portal and an additional 30 utilities accept applications via email (NREL 2021; Cook et al. 2021b). Interviewees suggested that these processes may reduce the time and cost required for application submission (if applications were previously submitted in-person or by mail) and reduce the administrative effort required by utility staff to file and track documents (even if previously submitted via email). For example, in 2017, the New York State Public Service Commission implemented the requirement for IOUs to use an application portal. ${ }^{14}$ This requirement could be one driver of the $60 \%$ decrease in pre-installation timelines reflected in our results. Analysis from O'Shaughnessy et al. (2022) further supports the conclusion that utilizing a portal is associated with a reduction in pre-installation application timelines by as much as a full business day.

Interviewees further suggested that implementing online payments or not charging fees at all, as opposed to requiring mail-in or in-person payment, can also improve review and approval timelines. However, if the utility does not charge a fee, it is likely that the cost of review will be incurred by all ratepayers, including those that do not have PV installed on their home or do not benefit directly from PV installations. NREL data shows that at least 41 utilities have no fee for interconnection applications within a certain threshold, and 18 other utilities accept payment online (NREL 2021; Cook et al. 2021b). ${ }^{15}, 16$ Although online payment systems can be integrated into an online application portal, not all utilities have implemented both practices together, which can influence overall review and approval timelines.

Finally, some utilities do not require pre-installation approval for systems meeting certain criteria. This allows the system to be installed without waiting for prior approval from the utility. Utilities without pre-installation approval requirements include the three largest California IOUs and at least 16 utilities across five other states (NREL 2021; Cook et al. 2021b). ${ }^{17}$ For California IOUs that do not require a pre-installation approval process, installers must use approved equipment (e.g., inverters, modules) from the California Energy Commission's database and

\footnotetext{
${ }^{14} 2017$ New York State Public Service Commission Standardized Interconnection Requirements and Application Process: documents.dps.ny.gov/public/Common/ViewDoc.aspx?DocRefId=\%7BA7780F50-4D4D-45D4-8B83A1832488C12D\%7D.

${ }^{15}$ This threshold is commonly set at $10 \mathrm{~kW}$ or $50 \mathrm{~kW}$.

${ }^{16}$ For example, IOUs in New York are not allowed to charge a fee for interconnection applications under $50 \mathrm{~kW}$, as mandated by the New York PSC, while San Diego Gas and Electric in California utilizes PayPal to allow interconnection application fee payments.

${ }^{17}$ Four more utilities are located in California, four in Florida, three in Texas, two in Nevada, one in Vermont, and one in Colorado.
} 
must meet specific size requirements, including being sized to offset only a certain percentage of the customer's load.

Data from SolarTRACE suggests that removing the pre-installation approval requirement could save 5 business days on average across the entire interconnection process (NREL 2021; Cook et al. 2021b). However, some interviewees questioned the feasibility of this approach for smaller utilities, especially where rooftop PV penetration is high and upgrades may be necessary to accommodate new installations. As such, this practice may be situationally limited. Some practices to alleviate the potential associated issues include having publicly accessible capacity hosting maps for the utility territory or linking application portals or associated application data with local load analysis tools.

\subsubsection{Common Barriers for Interconnection Applications and Practices To Overcome Them}

Although a variety of practices have been piloted and implemented across utilities to reduce interconnection timelines, many projects still take longer to approve than mandated by states.

Our interviews indicated that there are several reasons and related barriers faced by utilities of all sizes that can add time and cost to the interconnection process. Such barriers may include incomplete applications and problems with communication pathways, both externally (with installers) and internally (between utility departments). Utilities have taken various approaches to overcoming these barriers.

Incomplete and incorrect applications from PV installers and contractors were a commonly expressed concern from interviewed utilities. When applications are incomplete or incorrect, it takes time for a utility employee to address the issues and send them back to the installer for correction. In turn, the installer must then make updates and return a complete and accurate application, which may be placed at the end of the queue. For every error, this step must be repeated, which can result in extended total pre-application timelines from first submittal to final approval. Although utility review and approval times for each repeated submission may be compliant with state mandates, these projects nevertheless result in additional burdens to utilities and long wait times for both the customer and installer.

The issue of incomplete or incorrect applications can in some cases be addressed by adopting an application portal, thereby removing the back-and-forth between utilities and installers. However, a portal may not be able to catch the input errors or incorrect information that contribute to this issue. One unique practice that some utilities have employed is to offer regular training sessions for PV contractors to educate them on their interconnection application requirements. This approach may help mitigate some of the common mistakes made in applications that result in added time to the overall interconnection process.

Problems with internal communication were identified by multiple utilities as adding time to the process. Utility inspectors, engineers who review applications, and meter installers do not always work within the same interconnection or distributed generation department of the utility. These interactions require internal communication and documentation, which is not always a seamless process. These communication issues can add time delays to the interconnection process and can leave the installer and the customer feeling unclear about where they are in the process. Having a 
clear and streamlined internal — and subsequently external — communication process may aid in reducing this barrier and creating a more efficient interconnection process.

\section{Conclusions}

This report quantifies the median pre-installation approval timelines at the state level between 2017 and 2019 for 24 states, as well as the change in pre-installation approval timelines in five states. The key takeaways from this research include:

- Across the 24 analyzed states, pre-installation approval timeline mandates vary widely, ranging between 10 and 40 business days, and calculated median timelines range from 1 to 23 days.

- In seven of the analyzed states, $95 \%$ or more of projects $\leq 10 \mathrm{~kW}$ meet the respective state-mandated maximum timeline requirements, and in six of the analyzed states, $95 \%$ or more of projects $11-50 \mathrm{~kW}$ meet the timeline requirements.

- Short approval timelines do not always occur in states with more stringent timeline mandates, and likewise, the slowest timelines do not necessarily coincide with the least stringent mandates.

- For the five states in the historical analysis, the median timelines have declined by $57 \%-$ $100 \%$ for projects $\leq 10 \mathrm{~kW}$ and $44 \%-74 \%$ for projects $11-50 \mathrm{~kW}$.

This study looks at one important phase of the timeline from system sale to permission to operate (PTO). It is unclear how the pre-installation approval timeline impacts the overall timeline from sale to PTO. Reducing the time from system sale to PTO is imperative to the continued growth of PV deployment.

Although this study cannot confirm why some states or utility review and approval times are faster than others, interviews did provide some perspective regarding potential pathways to reduce review and approval timelines, including the removal of pre-installation approval processes and/or the proliferation of automated interconnection application and payment processes. Even so, interviewees suggested that these practices may not always have the intended effect of streamlining or otherwise improving processes.

Although this study adds to the existing literature, a significant gap still exists in the research on distributed PV interconnection timelines, best practices, and requirements. More research is required to analyze how other phases of the interconnection process are affecting overall timelines. Considering the number of projects that are potentially out of compliance with statemandated timelines, further research should explore which variables influence pre-installation interconnection timelines, the significant variability between states in both timelines and timeline mandates, the effects of timeline delays, and the repercussions of or incentives for meeting these mandates. How interconnection timelines nationwide have evolved over time also requires a more in-depth analysis. 


\section{Bibliography}

Ardani, Kristen, Carolyn Davidson, Robert Margolis, and Erin Nobler. 2015. A State-Level Comparison of Processes and Timelines for Distributed Photovoltaic Interconnection in the United States. Golden, CO: National Renewable Energy Laboratory. NREL/TP-7A40-63556. https://www.nrel.gov/docs/fy15osti/63556.pdf.

Barnes, Chelsea, J. Barnes, B. Elder, and B. Inskeep. 2016. Comparing Utility Interconnection Timelines for Small-Scale Solar PV. EQ Research Report. http://eq-research.com/wpcontent/uploads/2016/10/EQ-Interconnection-Timelines-2016.pdf.

Basso, T. 2014. IEEE 1547 and 2030 standards for distributed energy resources interconnection and interoperability with the electricity grid. Golden, CO: National Renewable Energy Lab. No. NREL/TP-5D00-63157. https://www.nrel.gov/docs/fy15osti/63157.pdf

Bird, Lori A., Francisco Flores-Espino, Christina M. Volpi, Kristen B. Ardani, David Manning, and Richard McAllister. 2018. Review of Interconnection Practices and Costs in the Western States. Golden, CO: National Renewable Energy Laboratory; Denver, CO: Western Interstate Energy Board (WIEB). NREL/TP-6A20-71232. https://www.nrel.gov/docs/fy18osti/71232.pdf.

Brown, Gwen. 2021. "Minnesota PUC Fines Xcel Energy \$1 Million for Interconnection Failures." Interstate Renewable Energy Council. https://irecusa.org/2021/01/minnesota-pucfines-xcel-energy-1-million-for-interconnection-failures/.

Cook, Jeffrey J., Jesse Cruce, Eric O'Shaughnessy, Kristen Ardani, Robert Margolis. 2021 a. "Exploring the Link Between Project Delays and Cancelation Rates in the U.S. Rooftop Solar Industry." Energy Policy 156: 112421. https://doi.org/10.1016/j.enpol.2021.112421.

Cook, Jeffrey, Jesse Cruce, Emily Fekete, and Shiyuan Sara Dong. 2021b. "Solar Permitting, Inspection, and Interconnection Cycletimes and Requirements." Golden, CO: National Renewable Energy Laboratory-Data (NREL-DATA). No. DE35658. https://data.nrel.gov/submissions/160.

Feldman, David, Vignesh Ramasamy, Ran Fu, Ashwin Ramdas, Jal Desai, and Robert Margolis. 2021. U.S. Solar Photovoltaic System and Energy Storage Cost Benchmark: Q1 2020. Golden, CO: National Renewable Energy Laboratory. NREL/TP-6A20-77324. https://www.nrel.gov/docs/fy21osti/77324.pdf.

Friedman, Barry, Kristen Ardani, David Feldman, Ryan Citron, Robert Margolis, and Jarett Zuboy. 2013. Benchmarking Non-Hardware Balance-of-System (Soft) Costs for U.S. Photovoltaic Systems, Using a Bottom-Up Approach and Installer Survey. Golden, CO: National Renewable Energy Laboratory. NREL/TP-6A20-60412. https://www.osti.gov/biblio/1107461.

Krasko, Vitaliy A., and Elizabeth Doris. 2013. "State Distributed PV Policies: Can Low Cost (to Government) Policies Have a Market Impact?" Energy Policy 59: 172-181.

https://www.sciencedirect.com/science/article/pii/S0301421513001699. 
NREL. 2021. "Solar TRACE." SolarAPP+. National Renewable Energy Laboratory. Accessed June 21, 2021. https://solarapp.nrel.gov/solarTRACE.

O'Shaughnessy, Eric, Shiyuan Dong, Jeffrey J. Cook, Jesse Cruce, Kristen Ardani, Emily Fekete, and Robert Margolis. 2022. "Effects of Local Permitting and Interconnection Requirements on Solar PV Installation Durations." Energy Policy 161: 112734.

O'Shaughnessy, Eric, Gregory F. Nemet, Jacquelyn Pless, and Robert Margolis. 2019. "Addressing the Soft Cost Challenge in US Small-Scale Solar PV System Pricing." Energy Policy 134: 110956. https://www.sciencedirect.com/science/article/pii/S0301421519305439.

Stanfield, Sky, Kathleen Kapla, Erica Schroeder McConnell, Rusty Haynes, and Kimberly Kooles. 2013. "Minimizing Overlap in PV System Approval Processes." Interstate Renewable Energy Council. https://irecusa.org/resources/minimizing-overlap-in-pv-systemapprovalprocesses-case-studies-analysis/.

Taylor, Margaret. 2019. Understanding Streamlined Solar Permitting Practices: A Primer. Berkeley, CA: Lawrence Berkeley National Laboratory. https://escholarship.org/content/qt4sd69014/qt4sd69014.pdf.

Wood Mackenzie. 2021. "Latest Quarterly and Annual US PV Historical Data Release: 2020 Year-In-Review." Wood Mackenzie. https://power-andrenewables.woodmac.com/reportaction/469619/Toc. 